\title{
Evaluation of Phytochemical Content and Antioxidant Capacity of Processed Fenugreek (Trigonella foenum-graecuL.) Flour Substituted Injera
}

\author{
Daka Daka Godebo $^{1 *} \quad$ Engida Dessalegn $^{2} \quad$ Gezahegn Nigusse ${ }^{1}$ \\ 1.School of Nutrition, Food Science and Technology, College of Agriculture, Hawassa University, Hawassa, \\ Ethiopia \\ 2.Department of Chemistry, Hawassa College of Education, P.O. Box 115, Hawassa, Ethiopia
}

\begin{abstract}
Injera, is cultural food of some East African Countries particularly Ethiopia, Eritrea and to some extent Somalia which prepared from cereals such as teff, sorghum and maize. Fenugreek (Trigonella foenum-graecum L.) provides various active compounds that are essential for health promotion, disease prevention and food preservation. It can be exploited as functional and nutritional foods as well as therapeutic agent. This study was conducted to evaluate phytochemical contents and antioxidant capacity of fenugreek (roasted, germinated or raw) flour substituted teff injera. Phytochemical contents of total flavonoid content (TFC) and total condensed tannin content (TCTC) of fenugreek substituted injera were determined using aluminum chloride colorimetric and vanillin $\mathrm{HCl}$ assay methods respectively. DPPH (2, 2-Diphenyl-1-Picrylhydrazyl) scavenging (\%) and reducing power were taken as evaluation parameters for determination of antioxidant capacity of fenugreek substituted injera. The highest TFC (117.4 $\pm 1.56 \mathrm{mg}$ of cathechin equivalent/g of dried extract) and TCTC (18.44 \pm 0.48 $\mathrm{mg}$ of cathechin equivalent/g of dried extract) contents were found in 5\% roasted and 5\% raw fenugreek substituted injera respectively. The 5\% roasted fenugreek substituted injera showed strongest, DPPH radical scavenging activity $\left(\mathrm{IC}_{50}=0.27 \pm 0.05 \mathrm{mg} / \mathrm{mL}\right)$ and ferric ion reducing power $\left(\mathrm{IC}_{50}=0.89 \pm 0.05 \mathrm{mg} / \mathrm{mL}\right)$ than the other tested injera samples. In conclusion substitution of processed (roasted and germinated) fenugreek flour with teff flour showed more improvement in antioxidant capacity and total flavonoid content than that of raw fenugreek flour substituted injera.
\end{abstract}

Keywords: Phytochemical contents, Antioxidant capacity, processed fenugreek flour, teff flour

DOI: $10.7176 / \mathrm{FSQM} / 91-02$

Publication date:October $31^{\text {st }} 2019$

\section{Introduction}

Injera, is cultural food of some East African Countries particularly Ethiopia, Eritrea and to some extent Somalia (Mogessie, 2006). The principal use of injera production constitutes $70 \%$ of Ethiopians diet (Abebe et al. 2007). The synthetic preservatives, which have been used in foods for decades, may lead to negative health consequences. Therefore, there has been increasing interest to replace synthetic preservatives with natural effective and nontoxic compounds (Souza et al. 2005).

Spices contains natural chemicals like flavonoids, phenolic compounds that offer intrinsic ability to protect products by inhibiting oxidation and certain enzymatic reactions occurring in the food stuffs (Nanditha and Prabhasankar, 2009). Fenugreek has been used as food spice and medicinal plant in many countries for centuries and it is a good source of antioxidant (Bemihiretu et al. 2013). According to Tamiru and Kumar (2018) it has been possible to increase availability of bioactive compound in fenugreek seeds by employing various processing methods such as soaking, germination, roasting. As importance of this study, few researches has been done on raw fenugreek substituted injera (Bemihiretu et al. 2013); to our evidence, no study has been conducted on roasted and germinated fenugreek substituted injera for their possible phytochemical content, antioxidant activities. Therefore, this study was intended to evaluate fenugreek (roasting, germination and raw) substituted injera for their phytochemical contents (total flavoinoid and total condensed tannin) and antioxidant capacities (DPPH Scavenging and ferric reducing power).

\section{Materials and Methods}

Experimental site and Area of Sample collection

The experiment was conducted at Hawassa Univesity, College of Agriculture, School of Nutrition, Food Science and Technology. Hunda'ol fenugreek seed variety (Figure 1-a) was obtained from Sinana Agricultural Research Centre (SARC) found in Oromia National State, Bale Robe Sinana district. The cross-37 teff variety (Figure 1-b) was also obtained from Ethiopian Seed Enterprise of South Nation Nationality and Peoples' Region, Hawassa Branch Office, Ethiopia. 


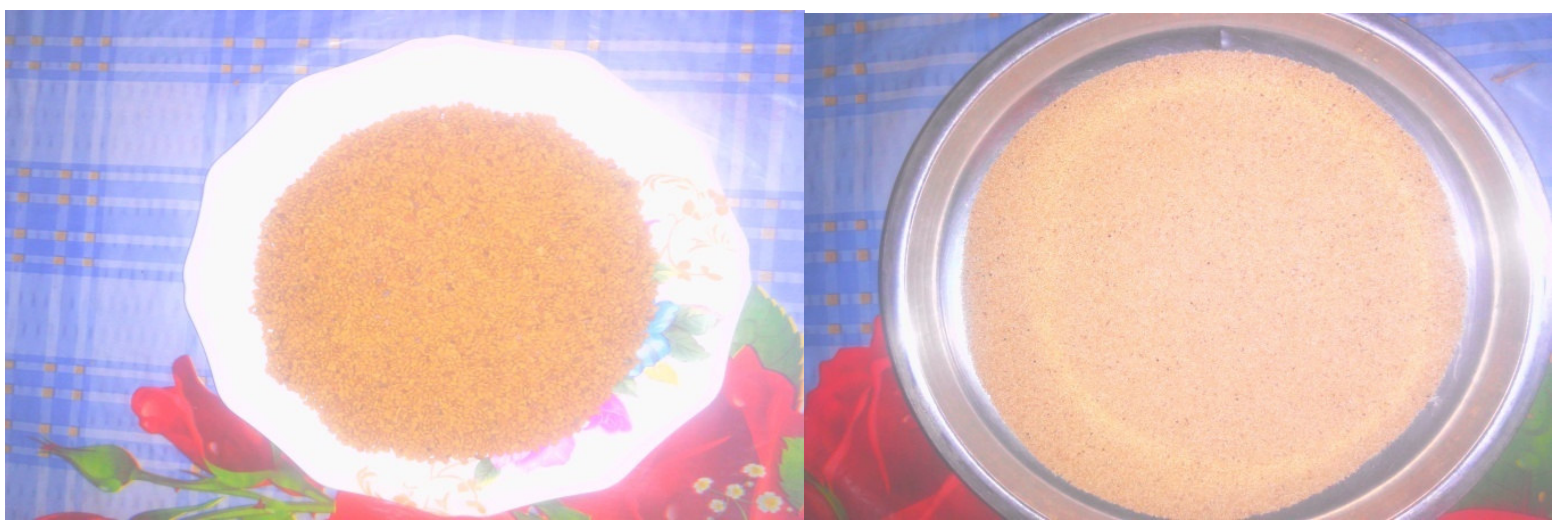

(a)

(b)

Figure 1. Hunda'ol fenugreek seed variety (a) and Cross-37 teff variety (b)

\section{Sample Preparation \\ Roasting of fenugreek}

Fenugreek seed was cleaned, graded, sorted and roasted at $90^{\circ} \mathrm{C}$ in an open pan for 4 minutes. It was continuously stirred with ladle for proper and uniform roasting until it became slight brown and left a peculiar aroma (Hemlata and Pratima, 2015).

\section{Germination of fenugreek}

It was cleaned and washed three times by using potable water. Then, the seed was soaked in potable water for 24 hours at room temperature with ratio of seeds: water $(1: 5 \mathrm{w} / \mathrm{v})$. The soaked seed was germinated in plastic sieves by covering sterilized cloth for 48 hours at room temperature with frequent watering interval of 12 hour. Then the germinated fenugreek seed was dried in open air (Ibrahium and Hegazy, 2009).

\section{Grinding of samples}

Fenugreek seeds of raw, germinated and roasted were ground in grinder (JFSO-100) and passed through standard test sieve by 500micrometer (ISO-3310-1 BODY S-STEEL made in Germany) to get uniform sized flour. The flours were collected and stored in polyethylene bag separately for further use at ambient temperature (Ibrahium and Hegazy, 2009). The cleaned teff was ground as home set level injera making. The ground teff powder was collected, packed and stored in dry polyethylene bags to be used in further injera making processes (Bemihiretu et al. 2013).

\section{Substitution of fenugreek seed flour with teff flour}

The findings of Hussein et al. (2011); Nabila et al. (2012); Atlaw and Jha (2015) showed that the raw and germinated fenugreek seeds flour substituted from 5-10\% with cereals (maize and wheat) flour was improved nutritive values, acceptable sensory and reduced microbial load status of biscuit and bread. Based on these trends, fenugreek (roasted, germinated and raw) seed flour substituted at 1\%, $5 \%$ and $10 \%$ with teff flour to make injera. The substituted flour (fenugreek flour with teff flour), was homogenized, packed in polyethylene bags and stored at room temperature for further use of injera making (Table 1).

Table 1. Substitution of fenugreek seed flour with teff flour to make injera

\begin{tabular}{llll}
\hline $\begin{array}{l}\text { Substitution } \\
\text { level of FSF:TF }\end{array}$ & Raw FSF : TF & Roasted FSF:TF & Germinated FSF:TF \\
\hline $0: 100$ & Control & Control & control \\
$1: 99$ & RAF1\% & ROF1\% $\%$ & GEF1\% \\
$5: 95$ & RAF5\% & ROF5\% & GEF5\% \\
$10: 95$ & RAF10\% & ROF10 $\%$ & GEF10\% \\
\hline
\end{tabular}

$\mathrm{FSF}=$ fenugreek seed flour; $\mathrm{TF}=$ teff flour; ROF5\% $=5 \%$ roasted fenugreek substituted injera; $\mathrm{ROF} 1 \%=1 \%$ roasted fenugreek substituted injera; GEF 5\%=5\% germinated fenugreek substituted injera; GEF1\%=1\% germinated fenugreek substituted injera; RAF5\% $=5 \%$ raw fenugreek substituted injera; RAF1\% $=1 \%$ raw fenugreek substituted injera

\section{Development of fenugreek substituted injera}

The fenugreek substituted injera samples were prepared at laboratory in same set as done at home level in the form of teff flour (FSF) substituted at 1\%,5\% and 10\% flour of fenugreek + water + starter (ersho). Accordingly, fenugreek substituted teff flour was mixed with clean water in the ratio 1:2 (w/v) and 16\% of starter (ersho) by 
weight of flour and was kneaded by hand in a bowl. The resultant dough was allowed to ferment for 3 days at ambient temperature (Ashagrie and Dawit, 2012).

After this primary fermentation, surface water formed on top of dough discarded. For every $1 \mathrm{~kg}$ of original flour, $200 \mathrm{~mL}$ of fermented mixture was mixed and with about $400 \mathrm{~mL}$ of water and brought to boil (traditionally known as absit making). It was cooled before it was added into main part of dough (Ashagrie and Dawit, 2012). The main dough was thinned by adding water equal to original weight of flour and stirred for 15 minute. The batter was left covered for 2 hours for secondary fermentation. After 2 hours, the absit was added to thinned dough and mixed very well (known as batter making). The batter was left for about 30 minute to rise before baking being started. Some more water was added to thin and form the right batter consistency.

Finally, about $500 \mathrm{~mL}$ of batter was poured onto hot clay griddle (mitad) in a circular motion from outside, working towards the centre. After 2-3 minute of cooking injera was removed and stored in a traditional basket container (messob). Immediately after cooling for a while (3 to 4 minute) the baked injera was stacked in a messob in which clean white polyethylene plastic was placed underneath of injera. Injera samples were then wrapped with white polyethylene plastic before placing messob lid as practiced at home set.

Then injera was packed in white polyethylene plastic bags and stored at room temperature until further study (Mogessie 2006; Ashagrie and Dawit 2012). However, injera containing 10\% fenugreek flour was excluded from this study, because of its unacceptability in all sensory properties.

\section{Extraction of fenugreek substituted injera}

Fresh baked injera was dried in open air at ambient temperature and ground using mortar and pestle to pass $500 \mu \mathrm{m}$ sieve as described by Tewodros et al. (2013). The $80 \%$ methanol extracts were prepared by dissolving $10 \mathrm{~g}$ of the injera samples flour separately. The contents were kept in orbital shaker for 8hours at room temperature. Thereafter, each extract was filtered using watt man № 3 filter paper and evaporated to dryness under vacuum at $40^{\circ} \mathrm{C}$ by using a hot air oven dry. For each injera sample, extraction done in duplicate and resulting extracts kept in a sealed dark glass bottle and stored at $4^{\circ} \mathrm{C}$ until further investigation (Engida, 2015). The extraction yield of each extract was obtained using the formula (W2-W1)/W0, where W2 was the weight of dried extract and container, W1 the weight of container alone and W0 the weight of dried sample. The result was expressed in terms of $\mathrm{mg}$ of dried extract per $\mathrm{g}$ of dried sample $(\mathrm{mg} / \mathrm{g})$.

\section{Phytochemical Content Analysis of Fenugreek Substituted Injera \\ Total flavonoid content (TFC)}

Total flavonoid content (TFC) of the extracts was determined by using the aluminum chloride colorimetric method as described by Bahzad et al. (2016). The extract $(1 \mathrm{~mL}, 10 \mathrm{mg} / \mathrm{mL})$ was diluted with $1.25 \mathrm{~mL}$ distilled water. At zero time, $75 \mu \mathrm{L} 5 \% \mathrm{NaNO}_{2}$ was added to the mixture. After 6 minute, $150 \mu \mathrm{L} 10 \% \mathrm{AlCl}_{3}$ was added. After another 5 minute, $1 \mathrm{~mL} 1 \mathrm{M} \mathrm{NaOH}$ was added to the mixture. Immediately, the absorbance of the mixture, pink in color was determined at 510nm spectrophotometer (JENWAY 6300) versus prepared distilled water as blank. Total flavonoid content was determined by using a standard curve $\left(y=0.011 x+0.132, R^{2}=0.97, p<\right.$ $0.001)$ of catechin $(10-100 \mu \mathrm{g} / \mathrm{mL})$ and values were calculated as $\mathrm{mg}$ catechin equivalents/g of dried extract (mg CE/g).

\section{Total condensed tannins content (TCTC)}

Total condensed tannin content (TCTC) was evaluated using vanillin assay method as described by Jeremiah et al. (2017). About $0.5 \mathrm{~mL}$ of $10 \mathrm{mg} / \mathrm{mL}$ of the extract sample solution was added to a mixture of $3 \mathrm{~mL} \mathrm{of} 4 \% \mathrm{w} / \mathrm{v}$ vanillin and $1.5 \mathrm{~mL}$ of hydrochloric acid, and then mixed. The mixture obtained was allowed to stand for 15 minute at room temperature and the absorbance was measured at $500 \mathrm{~nm}$ using spectrophotometer (JENWAY6300). The experiment was done in duplicate. Total condensed tannin content was calculated using the calibration curve $\left(\mathrm{y}=0.011 \mathrm{x}+0.132, \mathrm{R}^{2}=0.97, \mathrm{p}<0.001\right)$ a standard of catechin $(10-100 \mu \mathrm{g} / \mathrm{mL})$ and values were calculated as $\mathrm{mg}$ catechin equivalents/g of dried extract ( $\mathrm{mg} \mathrm{CE} / \mathrm{g}$ ).

\section{Antioxidant Capacity Evaluation of Fenugreek Substituted Injera DPPH scavenging (\%) activity}

The DPPH radical scavenging activity of the sample extracts were determined as follows. The different concentration $(0.05$ to $10 \mathrm{mg} / \mathrm{mL})$ of the extract was taken in different test tubes. Freshly prepared DPPH solution $(2 \mathrm{~mL}, 0.06 \%, \mathrm{~W} / \mathrm{V})$ in methanol was added in each of the test tubes containing $1 \mathrm{~mL}$ of the extract. The reaction mixture and reference standard (ascorbic acid) were vortexed and left to stand at room temperature in the dark for 30 minute. The absorbance of resulting solution then taken at $520 \mathrm{~nm}$ and methanol used as blank. The ability to scavenge DPPH radical was calculated as described by Engida (2015).

$$
\text { DPPH Scavenging }(\%)=(A C-A s) / A C \times 100
$$

Where $\mathrm{A}_{\mathrm{c}}$ was the absorbance of the control; $\mathrm{A}_{\mathrm{s}}$ was absorbance in presence of the sample of the extracts. 
The antioxidant activity of the extract was expressed as $\mathrm{IC}_{50}$; the $\mathrm{IC}_{50}$ value was defined as the concentration (in $\mathrm{mg} / \mathrm{mL}$ ) of extracts that scavenges DPPH radical by $50 \%$.

\section{Ferric ion reducing power}

The injera extract $(1 \mathrm{~mL}, 10 \mathrm{mg} / \mathrm{mL})$ solution was mixed with $2.5 \mathrm{~mL}$ sodium phosphate buffer $(0.2 \mathrm{M}, \mathrm{pH} 6.6)$ and $2.5 \mathrm{~mL}$ of $1 \%$ potassium ferricyanide. Then the mixture was incubated at $50^{\circ} \mathrm{C}$ for 20 minute. Trichloroacetic acid $(2.5 \mathrm{~mL}, 10 \%)$ was added to the mixture, then centrifuged at $3000 \mathrm{rpm}$ for 5 minute. Finally, $2.5 \mathrm{~mL}$ of the supernatant solution was mixed with $2.5 \mathrm{~mL}$ of distilled water and $0.5 \mathrm{~mL} \mathrm{FeCl}_{3}(0.1 \%)$ and absorbance was measured at $700 \mathrm{~nm}$. IC IC $_{50}$ values $(\mathrm{mg} / \mathrm{mL})$ were calculated by plotting absorbance against the corresponding sample concentration, representing the effective concentration at which the absorbance was 0.5 for reducing power (Meryem et al. 2016). The reducing power was calculated using the calibration curve ( $\mathrm{y}=$ $\left.0.0063 \mathrm{x}+0.148, \mathrm{R}^{2}=0.993, \mathrm{p}<0.01\right)$ a standard of ascorbic acid $(10-300 \mu \mathrm{g} / \mathrm{mL})$ and values were calculated as $\mathrm{mg}$ ascorbic acid equivalents/g of dried extract (mg AAE/g).

\section{Data Analysis}

The data were analyzed using one way analysis of variance (ANOVA) at 95\% level of confidence with SAS soft ware version 9 and $\mathrm{IC}_{50}$ values of antioxidant capacity was analyzed by origin pro 8 soft ware. The means of each parameter was compared using Fischer's least significant differences (LSD) procedures.

\section{RESULT and DISCUSSION}

\section{Extraction yield of Fenugreek Substituted Injera}

The data in Table 2 represent extraction yield ( $\mathrm{mg}$ of dried extract per $\mathrm{g}$ dried sample) of seven extracts of injera. The yields of seven extracts varied from 452.80 to $672.50 \pm 4.8 \mathrm{mg} / \mathrm{g} \mathrm{mg} / \mathrm{g}$ of dried extract. The ROF5\% gave highest yield $(672.50 \pm 4.8 \mathrm{mg} / \mathrm{g})$, while control extract gave the least yield $(452.80 \pm 2.5 \mathrm{mg} / \mathrm{g})$. The extract yield of injera decreased in order of roasted substituted $>$ germinated substituted $>$ raw fenugreek substituted injera and control. Injera substituted with roasted, germinated and raw fenugreek were significantly higher $(\mathrm{p}<$ $0.05)$ than that of control sample extract. Howe ever, GEF1\% and RAF1\% were not significantly $(p>0.05)$ different from control. The 5\% roasted, germinated and raw fenugreek substituted injera were significantly $(\mathrm{p}<$ 0.05 ) higher than $1 \%$ roasted, germinated and raw fenugreek substituted injera. These may be due to higher extractable phenolic compound and processing of fenugreek contributed, for increment of extraction yield (Manju et al. 2016).

Table 2. Extraction yield, total flavonoid content (TFC) and condensed tannin content (TCTC) of injera

\begin{tabular}{llll}
\hline Injera & $\begin{array}{l}\text { Extract yield } \\
(\mathrm{mg} / \mathrm{g} \text { of DW) }\end{array}$ & $\begin{array}{l}\text { TFC } \\
(\mathrm{mg} \text { of CE / 100g) }\end{array}$ & $\begin{array}{l}\text { TCTC } \\
(\mathrm{mg} \mathrm{of} \mathrm{CE} \mathrm{/} \mathrm{100g)}\end{array}$ \\
\hline Control & $452.80 \pm 2.5^{\mathrm{e}}$ & $17.59 \pm 2.63^{\mathrm{f}}$ & $1.54 \pm 0.48^{\mathrm{g}}$ \\
ROF5\% & $672.50 \pm 4.8^{\mathrm{a}}$ & $117.4 \pm 1.56^{\mathrm{a}}$ & $15.81 \pm 0.17^{\mathrm{b}}$ \\
GEF5\% & $555.50 \pm 1.5^{\mathrm{b}}$ & $94.45 \pm 2.92^{\mathrm{b}}$ & $11.42 \pm 0.31^{\mathrm{c}}$ \\
RAF5\% & $533.00 \pm 4.74^{\mathrm{c}}$ & $81.56 \pm 2.8^{\mathrm{c}}$ & $18.44 \pm 0.48^{\mathrm{a}}$ \\
ROF1\% & $498.60 \pm 3.6^{\mathrm{d}}$ & $78.43 \pm 3.04^{\mathrm{c}}$ & $5.57 \pm 0.51^{\mathrm{e}}$ \\
GEF1\% & $471.30 \pm 7.8^{\mathrm{e}}$ & $53.3 \pm 2.32^{\mathrm{e}}$ & $2.85 \pm 0.35^{\mathrm{f}}$ \\
RAF1\% & $460.00 \pm 4.3^{\mathrm{e}}$ & $47.3 \pm 2.12^{\mathrm{e}}$ & $9.64 \pm 0.48^{\mathrm{d}}$ \\
\hline
\end{tabular}

$\mathrm{DW}=$ dried weight of the injera; ROF $\%=5 \%$ roasted fenugreek substituted injera; ROF $1 \%=1 \%$ roasted fenugreek substituted injera; GEF 5\%=5\% germinated fenugreek substituted injera; GEF1\% $1 \%$ germinated fenugreek substituted injera; RAF5\% $=5 \%$ raw fenugreek substituted injera; RAF1\% $=1 \%$ raw fenugreek substituted injera; Values are expressed as mean $\pm \mathrm{SD}(\mathrm{n}=2)$ from duplicate experiments; Means with different letters in a column were significantly different at the level of $\mathrm{p}<0.05$

\section{Phytochemical Content of fenugreek substituted injera \\ Total flavonoid content (TFC)}

Plant flavonoids present in foods have received considerable attention because of their potential antioxidant activity (Boulanouar et al. 2013). The highest TFC found in ROF5\%, followed by GEF5\% and RAF5\%. This may be due to that roasting and germination of fenugreek seed provide more flavinoid bioavailability than that of raw fenugreek seed (Hemlata and Pratima , 2015). The TFC of all fenugreek substituted injera, was significantly $(\mathrm{p}<0.05)$ higher as compared to control. The TFC of GEF1\% and RAF1\% were not significantly different $(\mathrm{p}>$ $0.05)$ but, significantly higher $(\mathrm{p}<0.05)$ than that of control. Similar trends were reported by Bahzad et al. (2016) on fenugreek supplemented bread. 


\section{Total condensed tannins content (TCTC)}

Tannins were responsible for the brown, dark color and bitter taste of injera (Senayit et al. 2005). The highest total content of condensed tannin was observed in RAF5\% and the lowest TCTC was in GEF1\%. The TCTC of roasted and germinated fenugreek substituted injera were significantly $(\mathrm{p}<0.05)$ lower as compared to raw fenugreek substituted injera. The decreasing of TCTC in processed fenugreek substituted injera may be due to the breakdown of bond between anti nutritional factors (tannin) during roasting (Manju et al. 2016) and hydrolysis during germination process (Saini et al. 2016) of fenugreek seed. Similar trend was reported by Shimelis and Rakshit (2007) for effect of processing on anti nutrients of kidney bean.

\section{Antioxidant Capacity of Fenugreek Substituted Injera DPPH scavenging (\%) activity}

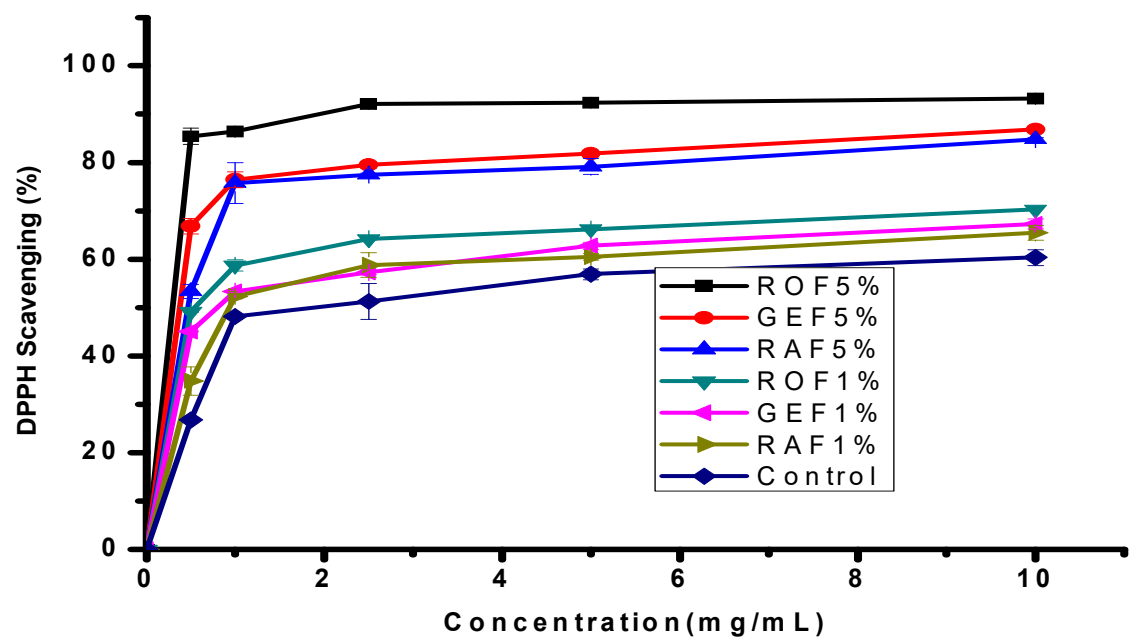

Figure 2. 2, 2-Diphenyl-1-picrylhydrazyl (DPPH) radical scavenging activity of roasted, germinated and raw fenugreek substituted injera; Values are expressed as mean $\pm \mathrm{SD}(\mathrm{n}=2)$ from duplicate experiments

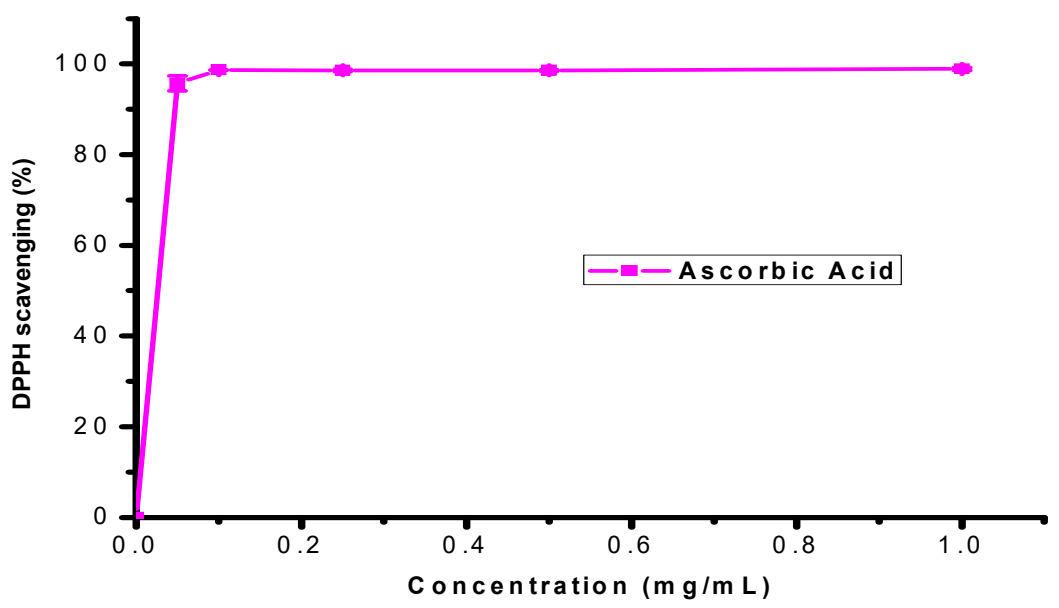

Figure 3. 2, 2-Diphenyl-1-picrylhydrazyl (DPPH) radical scavenging activity of ascorbic acid for reference; Values are expressed as mean $\pm \mathrm{SD}(\mathrm{n}=2)$ from duplicate experiments

Scavenging the stable DPPH radical model is a widely used method to evaluate in vitro antioxidant activity. DPPH is a stable free radical with characteristic absorption at $520 \mathrm{~nm}$ and antioxidants react with DPPH radical converted it to diamagnetic 2, 2-diphenyl-1-picrylhydrazine molecule. The degree of discoloration indicates scavenging potential of antioxidant of extract, which is due to hydrogen donating ability (Engeda, 2015).

Figure 2 showed that dose dependence curve for DPPH radical scavenging activity of roasted, germinated and raw fenugreek substituted and control, which quantified by its absorbance reduction at a wavelength of $520 \mathrm{~nm}$. As concentration of fenugreek increased, the percent of DPPH scavenging increased (Huang et al. 2005). The order of free radical scavenging capacity of fenugreek substituted injera and control were: ROF5\% > 
GEF5\% $>$ RAF5\% $>$ ROF $1 \%>$ GEF1\% $>$ RAF1\% > control injera, which were $93.2 \pm 0.28>86.85 \pm 0.21>$ $84.8 \pm 0.3>70.3 \pm 0.1>67.3 \pm 1.5>65.45 \pm 1.63>60.35 \pm 0.1)$ respectively.

As observed from above the free radical scavenging of roasted, germinated and raw fenugreek substituted injera were higher than that of control. However, raw fenugreek substituted injera extracts showed lower antioxidant activity as compared to roasted and germinated fenugreek substituted injera. Similarly, Saini et al. (2016) reported by that the DPPH scavenging of roasted and germinated fenugreek seeds were significantly higher than that of raw fenugreek seeds.

Table 3. The $\mathrm{IC}_{50}(\mathrm{mg} / \mathrm{mL})$ values of DPPH scavenging and ferric reducing power of injera

\begin{tabular}{llc}
\hline Injera & DPPH scavenging & Ferric reducing power \\
\hline Control & $1.96 \pm 0.02^{\mathrm{a}}$ & $8.34 \pm 0.09^{\mathrm{a}}$ \\
ROF5\% & $0.27 \pm 0.05^{\mathrm{g}}$ & $0.89 \pm 0.05^{\mathrm{g}}$ \\
GEF5\% & $0.36 \pm 0.01^{\mathrm{f}}$ & $1.90 \pm 0.03^{\mathrm{f}}$ \\
RAF5\% & $0.43 \pm 0.03^{\mathrm{e}}$ & $3.40 \pm 0.04^{\mathrm{e}}$ \\
ROF1\% & $0.52 \pm 0.07^{\mathrm{d}}$ & $3.94 \pm 0.01^{\mathrm{d}}$ \\
GEF1\% & $0.81 \pm 0.01^{\mathrm{c}}$ & $4.62 \pm 0.03^{\mathrm{c}}$ \\
RAF1\% & $0.95 \pm 0.06^{\mathrm{b}}$ & $6.61 \pm 0.06^{\mathrm{b}}$ \\
Ascorbic acid & $0.03 \pm 0.003^{\mathrm{h}}$ & $0.02 \pm 0.003^{\mathrm{h}}$ \\
\hline
\end{tabular}

ROF5\% $\%=5 \%$ roasted fenugreek substituted injera; ROF $1 \%=1 \%$ roasted fenugreek substituted injera; GEF $5 \%=5 \%$ germinated fenugreek substituted injera; GEF1 $\%=1 \%$ germinated fenugreek substituted injera; RAF5\% $=5 \%$ raw fenugreek substituted injera; RAF1\% $=1 \%$ raw fenugreek substituted injera; Values are expressed as mean \pm SD $(n=2)$ from duplicate experiments; Means with different letters in a column were significantly different at the level of $\mathrm{p}<0.05$

The $\mathrm{IC}_{50}$ was defined as concentration (in $\mathrm{mg} / \mathrm{mL}$ ) of extracts that scavenges DPPH radical by $50 \%$. The values of all extracts were calculated from graph of percentage of DPPH scavenging activity against concentration of extracts (Table 3). The lower $\mathrm{IC}_{50}$ value, the higher is scavenging potential. The $\mathrm{IC}_{50}$ values ranged from $0.27 \pm 0.05 \mathrm{mg} / \mathrm{mL}$ for $\mathrm{ROF} 5 \%$ and to $1.96 \pm 0.02 \mathrm{mg} / \mathrm{mL}$ for control. The DPPH scavenging activity of fenugreek substituted injera can be directly correlated with total phenolic contents in fenugreek seed (Dixit et al. 2005). This was in agreement with Bemihiretu et al. (2013) who reported that the white teff enriched with fenugreek, increased the DPPH scavenging activity of injera.

The strongest scavenging activity was recorded for ROF5\% which, appeared more than 7.25, 1.3 and 1.59 times stronger than that of control, GEF5\% and RAF5\% extracts respectively. This may be due to the synthesis of more phenolic compounds in roasted and germinated fenugreek which are responsible for antioxidant activity (Sharma and Gujral, 2010)but, all fenugreek substituted injera showed weaker DPPH scavenging activity ( $\mathrm{p}<$ $0.05)$ than that of ascorbic acid.

\section{Ferric ion reducing power}

Ferric ion $\left(\mathrm{Fe}^{+3}\right)$ reduction was used as an indicator of electron donating activity, which is an important mechanism in phenolic antioxidant reaction (Hinne et al. 2006). Therefore, concentration of $\mathrm{Fe}^{2+}$ (ferrous reduced one) was monitored by measuring formation of Perl's Prussian blue at $700 \mathrm{~nm}$ of spectrophotometer (Amarowicza et al. 2004).

Figure 4 showed that the roasted, germinated and raw fenugreek substituted injera and their substitution level effects on ferric ion reducing power. Similar to DPPH scavenging at concentration of $10 \mathrm{mg} / \mathrm{mL}$, ferric ion reducing power capacity of injera was decreased in the order of ROF5\% $>$ GEF5\% $>$ RAF5\% $>$ ROF $1 \%>$ GEF1\% $>$ RAF1\% $>$ control, which were $0.901 \pm 0.03 \mathrm{~nm}>0.84 \pm 0.04 \mathrm{~nm}>0.78 \pm 0.02 \mathrm{~nm}>0.75 \pm 0.04$ $\mathrm{nm}>0.72 \pm 0.01 \mathrm{~nm}>0.6 \pm 0.05 \mathrm{~nm}>0.54 \pm 0.02 \mathrm{~nm}$ respectively. The increased concentration of sample was showed, the higher absorbance of ferric reducing power. There were significant differences $(p<0.05)$ in $\mathrm{IC}_{50}$ values among fenugreek substituted injera in their ferric ion reducing ability; but these values were significantly $(\mathrm{p}<0.05)$ weaker as compared to ascorbic acid $(0.02 \pm 0.003 \mathrm{mg} / \mathrm{mL})$.

As observed from Table 3, ROF5\% showed significantly $(\mathrm{p}<0.05)$ strongest reducing activity, as compared to GEF5\%, RAF5\%, ROF1\%,GEF1\% and RAF1\%. However, all fenugreek substituted injera showed significantly $(\mathrm{p}<0.05)$ stronger reducing ability than that of control. This was in line with reports of Bahzad et al. (2016) that the fenugreek substitution was enhanced ferric reducing power of bread. 


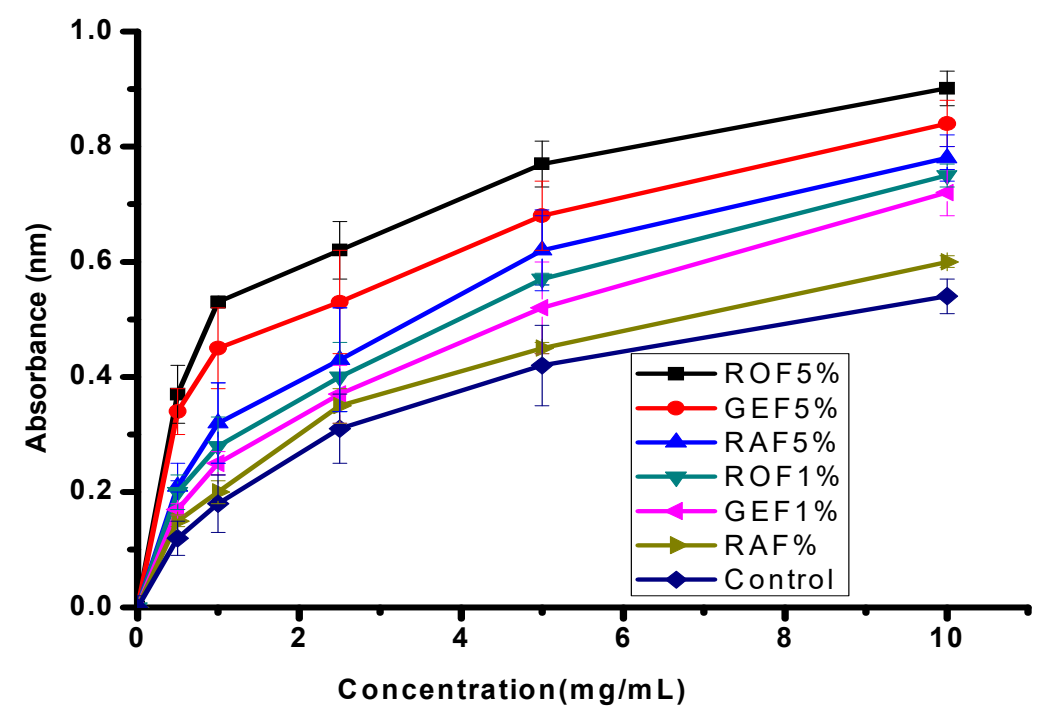

Figure 4. The Ferric ion reducing power of roasted, germinated and raw fenugreek substituted injera; Values are expressed as mean $\pm \mathrm{SD}(\mathrm{n}=2)$ from duplicate experiments

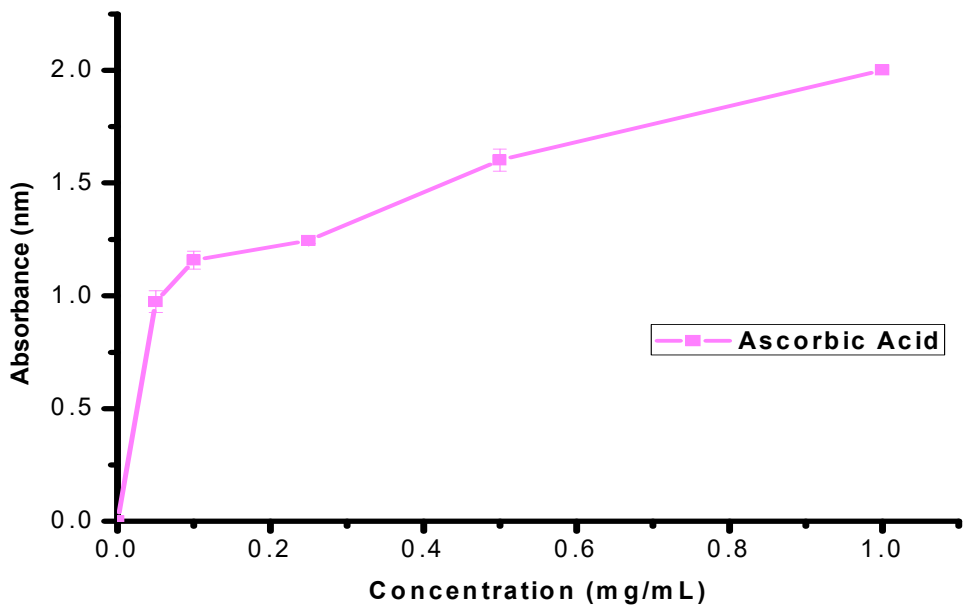

Figure 5. Ferric ion reducing power of ascorbic acid as reference; Values are expressed as mean $\pm \operatorname{SD}(n=2)$ from duplicate experiments

The reducing power of roasted fenugreek substituted injera found to be stronger than germinated fenugreek substituted injera. This may be due to roasting provided better reducing ability than germination of fenugreek. Similar trends were reported by Jeong et al. (2004), that the antioxidant activities of pulse like sesame significantly $(\mathrm{p}<0.05)$ increased with roasting time at $150{ }^{\circ} \mathrm{C}$ and $200{ }^{\circ} \mathrm{C}$. According to Han and Koh $(2011)$ longer baking times or higher temperatures of wheat flour generally corresponded to higher levels of antioxidants in comparison to less intense baking conditions. This was because most of the antioxidants found inside of bran and endosperm of the grain had been obtained in high temperature (Bemihiretu et al. 2013). According to the present observation, $5 \%$ roasted $\left(\mathrm{IC}_{50}=0.89 \pm 0.05 \mathrm{mg} / \mathrm{mL}\right)$ and $5 \%$ germinated $\left(\mathrm{IC}_{50}=1.90 \pm\right.$ $0.03 \mathrm{mg} / \mathrm{mL}$ ) fenugreek substituted injera showed stronger reducing ability than that reported by Bemihiretu et al. (2013), in which 5\% raw fenugreek enriched injera found to be $\mathrm{IC}_{50}$ of $2.7 \mathrm{mg} / \mathrm{mL}$. This probably due to varietal and processing technique difference (Saini et al. 2016).

\section{Conclusion}

The substitution of fenugreek flour in teff flour improved phytochemical (flavonoid and tannin) content, found to be increased with increased substitution level. It was revealed that fenugreek substituted injera contain a considerable amount of phenolic compounds and has significant antioxidant activities, which can be used as easily accessible source of natural antioxidants. 


\section{Acknowledgment}

Authors would like to greatly acknowledge Dr. Engida Dessalegn, my major advisor for his invaluable comments, suggestion and for his support of expensive laboratory analytical chemicals. I am also grateful to my co-advisor Mr. Gezahegn Nigusse for his heart felt comments and encouraging suggestions from the very beginning of research concept note, proposal development until full thesis.

\section{Conflict of Interest}

I declare that this thesis is my original work and all sources of materials used for this thesis have been duly acknowledged. I solemnly declare that this thesis is not submitted to any other institution anywhere for the award of any academic degree, diploma or certificate.

\section{References}

Abebe Y, Bogale A, Hambidge KM, Stoecker, Barbara JS, Karl B, Rosalind SG. 2007. Phytate, zinc, iron and calcium content of selected raw and prepared foods consumed in rural Sidama, Southern Ethiopia and implications for bioavailability. J Food Compos Anal 20 (3): 161 - 168.

Amarowicza R, Pegg R, Rahimi MP, Barld B, Weilc J. 2004. Free radical scavenging capacity and antioxidant activity of selected plant species from Canadian prairies. Food Chemistry 84:551 - 562 .

Ashagrie ZW, Dawit A. 2012. Improvement of injera shelf life through the use of chemical preservatives. AJFAND 12(5): $6409-6423$

Atlaw T K, Jha Y K. 2015. Evaluation of composite blends of fermented fenugreek and wheat flour to assess its suitability for bread and biscuit. Int J Nutri Food Sci 4(1):29 - 35.

Bahzad A, Imran P, Tahir Z, Haq N. 2016. Nutritional potential of fenugreek supplemented bread with special reference to antioxidant profiling. Pakistan J Agric Sci 53(1):217 - 223.

Bemihiretu B, Ashagrie ZW, Gulelat DH. 2013. Antioxidant properties of Ethiopian traditional bread (injera) as affected by processing techniques and teff grain (Eragrostis tef) varieties. Canadian Chemical Transactions $1: 7-24$.

Boulanouar B, Abdelaziz G, Aazza S, Custódia G C, Miguel MC. 2013. Antioxidant activities of eight Algerian plant extracts and two essential oils. Indian Crop Production 46: 85-96.

Dixit P, Ghaskadbi S, Mohan H, Devasagayam TP. 2005. Antioxidant properties of germinated fenugreek seeds. Phytotherapy Research 19: 977 - 983.

Engeda D.2015. In vitro antioxidant and $\alpha$-amylase inhibition activities of spiced red chili paste (datta) from South Ethiopia. Ethiopian Pharm J 31:93-106.

Han HM, Koh BK. 2011. Antioxidant activity of hard wheat flour, dough and bread prepared using various processes with the addition of different phenolic acids. J Food Sci Agric 91: $604-608$.

Hemlata P, Pratima A. 2015. Effect of processing techniques on nutritional composition and antioxidant activity of fenugreek (Trigonella foenum-graecum L.) seed flour. J Food Sci Technol 52 (2):1054 - 1060.

Hinne BI, Damien DHJ, Hiltunen R. 2006. Antioxidant activities of extract from selected culinary herbs and spices. Food Chemistry 97:122 - 129.

Huang D, Box O, Ronald LP. 2005. The chemistry behind antioxidant capacity assays. J Agric Food Chemistry 53:1841-1856.

Hussein AMS, Amal S, Abd E, Amany MH, Abeer A A, Gamal HR. 2011. Physiochemical, sensory and nutritional properties of corn- fenugreek flour composite biscuits. Aust J Basic Appl Sci 5(4): 84-95.

Ibrahium MI, Hegazy AI. 2009. Iron bioavailability of wheat biscuit supplemented by fenugreek seed flour. World J Agric Sci 5 (6): 769-776.

Jeremiah O U, Gloria AO, Anthony JA. 2017. Phytochemical screening and in vitro evaluation of antioxidant and antimicrobial activities of Kedrostis Africana L. Cogn. Asian Pacific Journal of Tropical Biomedicine $1-8$.

Jeong SM, Kim SY, Kim DR, Nam KC, Ahn DU, Lee SC. 2004. Effect of seed roasting conditions on the antioxidant activity of defatted sesame meal extracts. J Food Sci 69:1 - 5.

Manju, Parveen, Khatkhar BS. 2016. Effect of germination and roasting on nutritive composition and antinutrients in fenugreek seeds. IJSTE 3(06):31 - 35

Meryem E, Rabie K, Ilias M, Asmae Z, Yahia C, Katim A. 2016. Radical-scavenging activity and ferric reducing ability of Juniperus Thurifera L., J. Oxycedrus L., J. Phoenicea L. and Tetraclinis Articulata L. Advances in Pharmacological Sciences 1-6.

Mogessie A. 2006. Review on the microbiology of indigenous fermented foods and beverages of Ethiopia. Ethiop J Biol Sci 5(2): 189-245.

Nabila YM, Rabab HS, Amal AM. 2012. Nutritional and biological assessment of wheat biscuits supplemented by fenugreek plant to improve diet of anemic rats. Acad J Nutr 1 (1): 01-09.

Nanditha B, Prabhasankar P. 2009. Antioxidants in bakery Products. Critical Review of Food Science and 
Nutrition 49:1 - 27 .

Saini P, ND, Priyanka S, Anchal S. 2016. Effect of processing methods on proximate composition and antioxidant activity of fenugreek (Trigonella foenum-graecum L.) seedsInternational. Int J Agric Food Sci 6(2): 82-87.

Senayit Y, Rooney LW, Taylor JRN. 2005. Improving the quality of sorghum injera by de cortication and compositing with teff. J Sci Food Agric 85:1252 - 1258.

Sharma P, Gujral HS. 2010. Antioxidant and polyphenols oxidase activity of germinated barley and its milling fractions. Food Chemistry 120 (3): $673-678$.

Shimelis A, Rakshit SK. 2007. Effect of processing on anti nutrients and in vitro protein digestibility of kidney bean (Phaseolus vulgaris L.) varieties grown in East Africa. Food Chemistry 103: 161 - 172.

Souza EL, Tania LMS, Edeltrudes DL, Vinicius NT, Jose MBF. 2005. Antimicrobial effectiveness of spices: An approach for use in food conservation systems. BRAZ ARCH BIOL TECHN 48 (4): 549 - 558.

Tamiru KA, Kumar JY. 2018. Effect of germination on nutritional composition and functional properties of fenugreek (Trigonella foenum-graecum L.) seed flour. Food Science and Quality Management.76:18 - 23

Tewodros G, Geremew B, Negussie B. 2013. Effect of grain teff (Eragrostis tef) flour substitutions with flaxseed on mineral content, antioxidant activity, phytic acid content and microbial quality of injera. Sci Technol Arts Res J 2(3): 51-58.

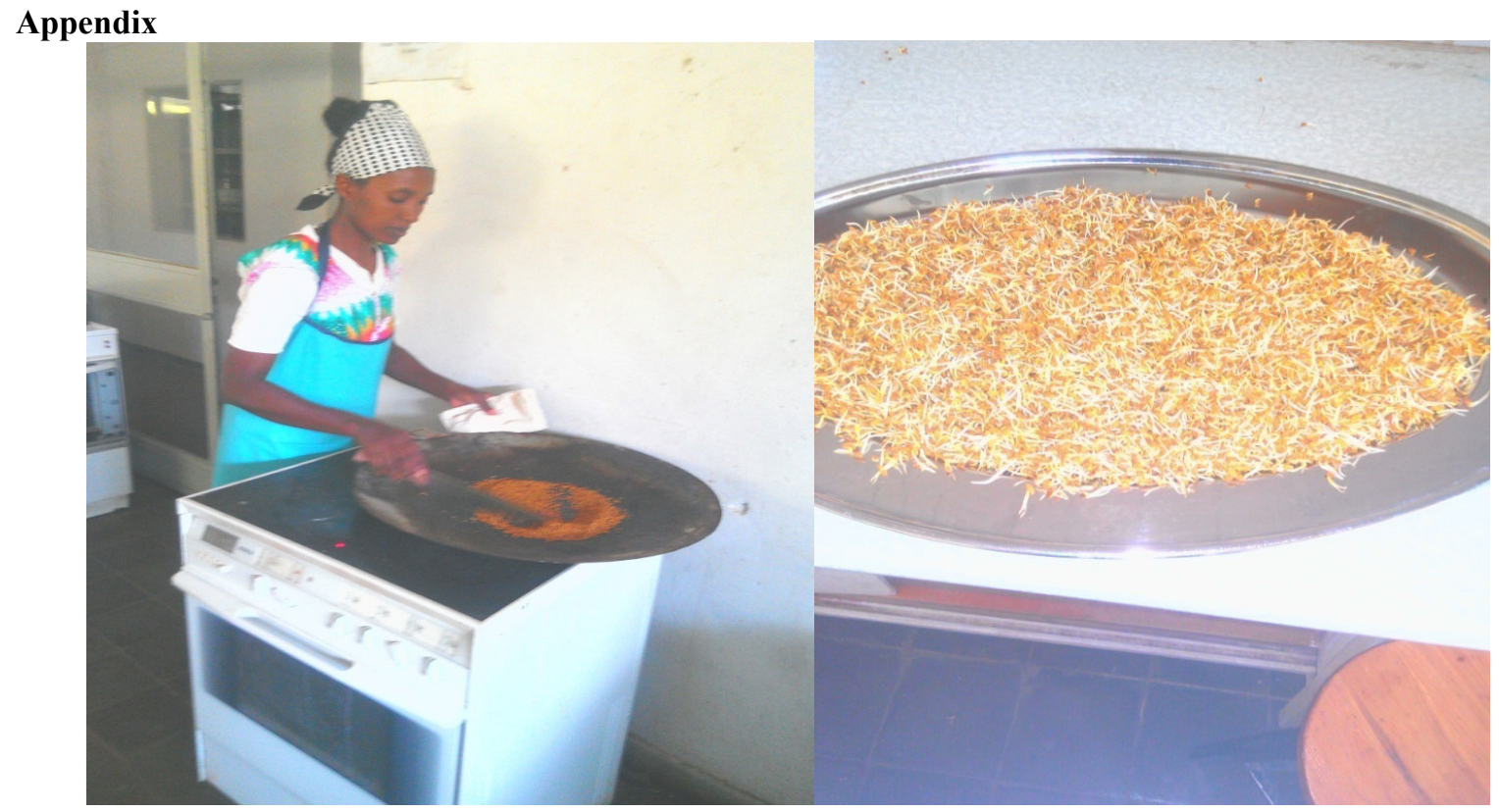

Processing (roasting and germination) of fenugreek seed 


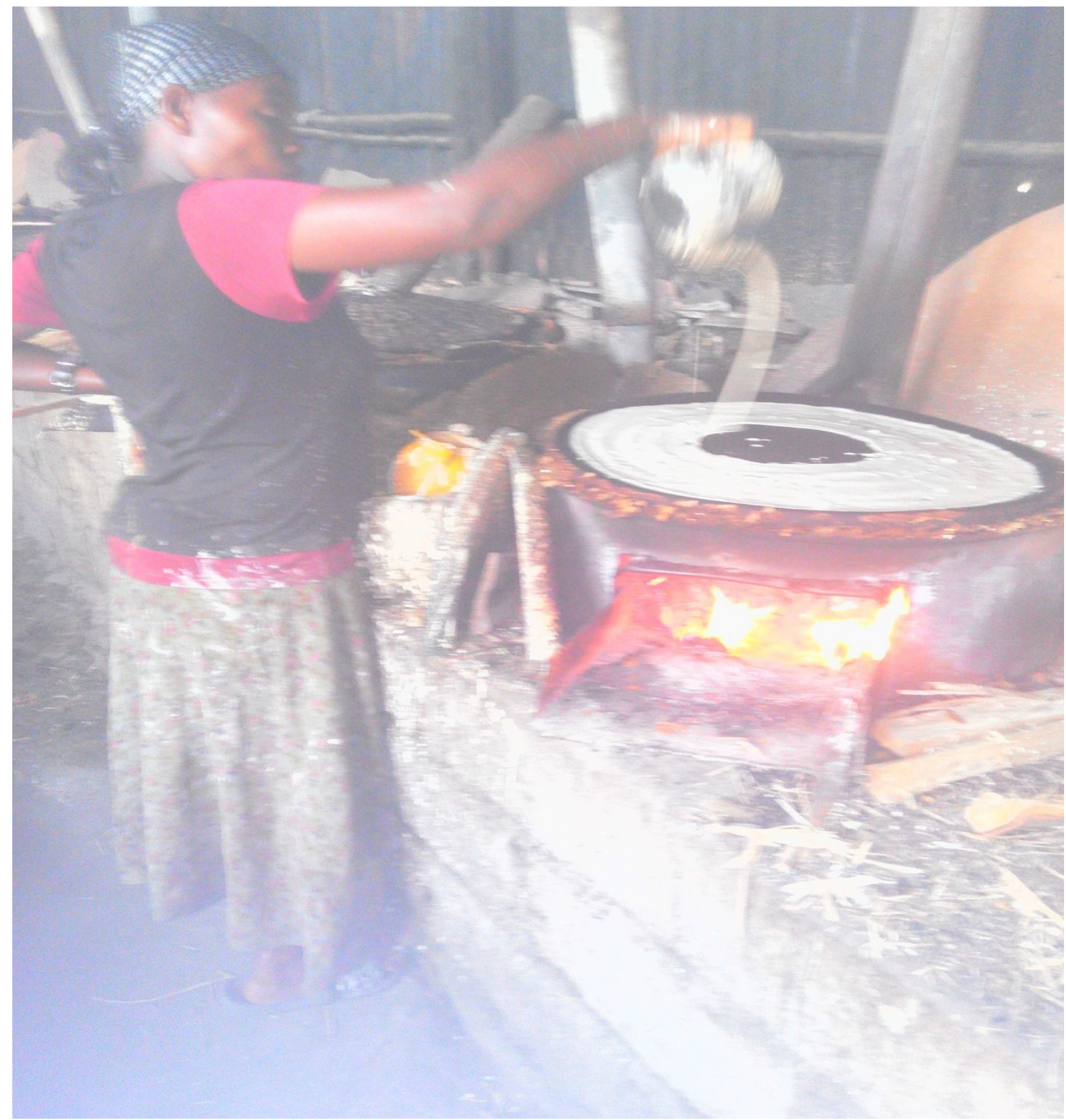

Making fenugreek (roasted, germinated and raw) substituted injera 